\title{
Temporal changes of phytoplankton community at different depths of a shallow hypertrophic reservoir in relation to environmental variables
}

\author{
YongSu Kwon ${ }^{1} \ddagger$, SoonJin Hwang ${ }^{2} \ddagger$, KuSung Park ${ }^{2}$, HoSeob Kim ${ }^{3}$, BaikHo Kim², \\ KyungHoon Shin ${ }^{4}$, KwangGuk An ${ }^{5}$, YoungHee Song ${ }^{6}$ and YoungSeuk Park ${ }^{1 *}$ \\ 1 Department of Biology and The Korea Institute of Ornithology, Kyung Hee University, Seoul 130701, Korea \\ 2 Department of Environmental Science, Konkuk University, Seoul 143701, Korea \\ 3 Watershed Management Research Divisions, National Institute of Environmental Research, Incheon 404170, Korea \\ ${ }^{4}$ Department of Environmental Marine Science, Hanyang University, Ansan 425791, South Korea \\ 5 School of Bioscience and Biotechnology, Chungnam National University, Daejeon 305764, South Korea \\ ${ }^{6}$ Rural Research Institute, Ansan 426908, South Korea
}

Received 15 January 2009; Accepted 8 April 2009

\begin{abstract}
We characterized phytoplankton community succession at different depths of a shallow hypertrophic reservoir in relation to physical and chemical environmental variables. The phytoplankton community was sampled biweekly at three different water depths (surface, middle and bottom) in the reservoir from November 2002 to February 2004. A range of 18 environmental variables including temperature, electrical conductivity (EC), total phosphorus (TP) and total nitrogen (TN) were measured to assess their influence on phytoplankton community succession. As well, combined multivariate analyses with a cluster analysis and a nonmetric multidimensional scale (NMDS) were conducted. Microcystis aeruginosa was the dominant species in all seasons except spring. Thus, Cyanophyceae was a dominant taxonomic group. In spring, Bacillariophyceae dominated, followed by Cryptophyceae and Chlorophyceae. The succession was relatively delayed at the middle and bottom layers compared with at the surface layer. Abundance and species richness of phytoplankton were also higher in the surface layer than in the bottom layer. Cluster analysis classified the phytoplankton community into four clusters at each depth, and the changes were also well reflected in the NMDS ordination. Each cluster showed seasonal patterns characterized by indicator species, as well as environmental variables such as temperature, conductivity, and nutrients including $\mathrm{N}$ and $\mathrm{P}$. Seasonal dynamics of the phytoplankton community was the strongest at the surface layer and weakest at the bottom layer. These depth-variable environmental variables are likely to be the key factors driving changes in the phytoplankton community composition.
\end{abstract}

Key words: Algae / classification / lakes / succession / vertical differences

\section{Introduction}

Changes in phytoplankton communities in lakes occur in space and time, and are related to the physical, chemical, and biological conditions of the water bodies (Reynolds, 1984; Wetzel, 2001; Valério et al., 2008). Temporal variability in the structure and function of the phytoplankton community in a lake is of fundamental importance to lake metabolism (Calijuri et al., 2002),

\footnotetext{
* Corresponding author.

E-mails: parkys@khu.ac.kr, sjhwang@konkuk.ac.kr

† These two authors contributed equally.
}

studies of which are important to aid understanding of lake ecosystems as well as for effective management of lake water quality. Many studies have investigated temporal changes in phytoplankton communities in lakes, including long-term changes (Reynolds, 1984; Romo and Miracle, 1994; Chen et al., 2003; Winder and Hunter, 2008) and seasonal dynamics (Salmaso, 1996, 2002; Wang et al., 2007). Typical seasonal succession models of the phytoplankton community in temperate lakes shows that Bacillariophyceae dominate during early spring, Chlorophyceae dominate in late spring, and Cyanophyceae dominate during summer (Reynolds, 1984). However, phytoplankton species composition and succession can 


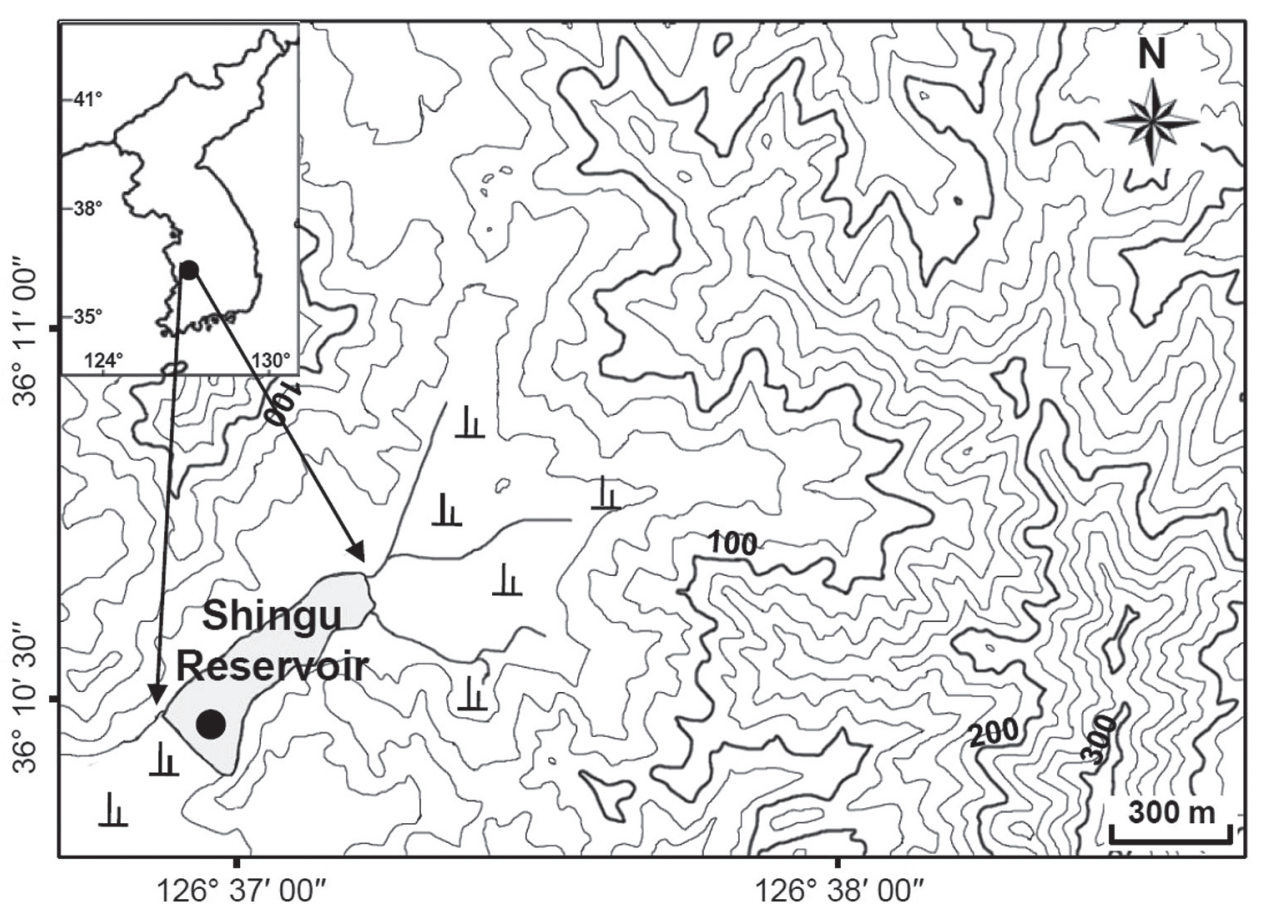

Fig. 1. Location of our sampling site $(\bullet)$ in the Shingu Reservoir (Chungcheongnamdo, Korea).

have diverse patterns depending on the environmental conditions (Abdul-Hussein and Mason, 1988; Wetzel, 2001; Reynolds, 2006). Additionally, phytoplankton communities can undergo significant changes within a single year (Padisak, 1992).

Variation in phytoplankton communities also occurs with depth in response to environmental conditions (Huovinen et al., 1999; Ptacnik et al., 2003; Reynolds, 2006). The vertical distribution of phytoplankton in lakes appears to be affected by factors that include light, temperature, nutrients, predation, and mixing patterns within the water column, and, thus, their composition and biomass varies with depth (Huisman et al., 1999; Gervais et al., 2003; Ptacnik et al., 2003; Pinilla, 2006). In particular, the influences of the gradient of incident light and mixing patterns in the water column have been studied as niches for different groups of species related to their motility, buoyancy, and size (Huisman et al., 1999; Ptacnik et al., 2003). The combination of nutrient availability and temperature is also a key factor in the spatial and temporal dynamics of phytoplankton, and affects their productivity and growth period (Reynolds, 1984, 1988; Wetzel, 2001).

As such, phytoplankton succession of lentic systems is generally understood as the outcome of the complicated interactions in the water column. The succession, however, does not necessarily indicate the 'mean' or 'integrated' interaction through the whole water column. Vertical distribution of phytoplankton in deep oligotrophic lakes seems to be distinct depending primarily on light availability (Brook and Torke, 1977; Tilzer et al., 1977) and algal adaptation to low light intensities (Priscu and Goldman, 1983), and it is likely separated by stratification. Distinct vertical distribution may not be evident in shallow systems, due to more probable mixing and resuspension. Despite this rationale, little information is available on spatial phytoplankton succession in shallow lentic systems. Thus, it is worth investigating the succession of phytoplankton at different depths of a shallow system, because the results provide basic information on how shallow lentic systems drive phytoplankton succession, whether phytoplankton succession is characteristic along the depth profile, and to clarify the major variables at different depths. The results will contribute to an increased understanding of the integrated phytoplankton dynamics in shallow eutrophic reservoirs.

The objective of this study was to assess phytoplankton community succession at different water depths of a hypertrophic reservoir. Various approaches were used to analyze temporal changes in the community in relation to environmental variables, including community indices, hierarchical cluster analysis, nonmetric multidimensional scale, and indicator species analysis.

\section{Materials and methods}

\section{Study area}

The study was conducted at the Shingu Reservoir, a shallow hypertrophic agricultural reservoir located in Chungcheongnamdo, Korea $\left(36^{\circ} 10^{\prime} 31.37^{\prime \prime} \mathrm{N}\right.$, $126^{\circ} 37^{\prime}$ 02.24" E) (Fig. 1). The reservoir has a surface area of $0.1 \mathrm{~km}^{2}$, mean depth of $3.9 \mathrm{~m}$, catchment area of $2.55 \mathrm{~km}^{2}$, and water storage capacity of $411 \times 10^{3} \mathrm{~m}^{3}$. There are two inflowing streams with a $1.3 \mathrm{~km}$ and $3.4 \mathrm{~km}$ channel length, respectively. Water quality 
in the reservoir is affected by livestock waste from farms near the reservoir, and the water level is influenced by precipitation during the summer monsoon as well as from irrigated paddy fields (KARICO, 2001). Oxygen depletion has been recorded in the reservoir during summer, while the water surface freezes during winter (Kim, 2004).

\section{Sample collection}

Phytoplankton samples were collected biweekly from the bank near the deepest point in the reservoir from November 2002 to February 2004. Samples were not collected between January and February 2003 due to thick ice cover on the reservoir. Samples were collected from three different depths (surface, middle and bottom layers) at $2 \mathrm{~m}$ intervals. Water samples $(100 \mathrm{~mL})$ for the identification of phytoplankton species and measurement of cell densities were stored in Whirl-Pak bags and fixed with Lugol's solution ( $2 \%$ final concentration). Cell densities were measured by microscopy (Axiostar plus; Zeiss, Germany) using a Sedgwick-Rafter counting chamber at 200-400 × magnification. Phytoplankton were identified to species as described previously (Prescott, 1962; Hirose and Yamagishi, 1977; John et al., 2003).

Temperature, dissolved oxygen (DO), $\mathrm{pH}$, and electric conductivity were measured using an in situ RE232/SDI12 data logger (Hydrolab, USA) at each depth. Secchi depth was measured using $20 \mathrm{~cm}$ diameter Secchi discs. For nutrient analyses, $5 \mathrm{~L}$ water samples collected at each depth using a Van Dorn sampler (WildCo., USA) were placed in sterilized polyethylene bottles and were transported to the laboratory on ice. Total phosphorus (TP), total dissolved phosphorus (TDP), and dissolved inorganic phosphorus (DIP) were analyzed in triplicate using the ascorbic acid method (APHA, 1995). Particulate organic phosphorus (POP) was determined by subtraction of the TDP value from the TP value. Total nitrogen (TN) was measured using the cadmium reduction method following persulfate digestion (APHA, 1995). Ammonia nitrogen $\left(\mathrm{NH}_{3} \mathrm{~N}\right)$ was measured using an indolphenol reagent, and nitrite nitrogen $\left(\mathrm{NO}_{2} \mathrm{~N}\right)$ and nitrate nitrogen $\left(\mathrm{NO}_{3} \mathrm{~N}\right)$ were measured using the cadmium reduction method (APHA, 1995). Dissolved inorganic nitrogen (DIN) was calculated as the sum of $\mathrm{NO}_{3} \mathrm{~N}, \mathrm{NO}_{2} \mathrm{~N}$ and $\mathrm{NH}_{3} \mathrm{~N}$. Suspended solids (SS) and the chemical oxygen demand (COD) were measured using standard methods (APHA, 1995).

The total dataset comprised 63 samples (22 surface layer, 20 middle layer, and 21 bottom layer samples) of the phytoplankton community and 18 environmental factors.

\section{Data analysis}

Community indices including species richness, abundance, and species diversity index were estimated at each water depth and sampling time. For each sample, species richness and abundance were expressed as the number of species and cell density, respectively. Species diversity was estimated according to the Shannon index (Shannon, 1948). Pearson correlation coefficients were calculated among environmental variables. The Kruskal-Wallis (KW) test was used to assess differences in community indices at the different depths, and the nonparametric Dunn's multiple comparisons test was done for post hoc comparisons. The analyses were made using STATISTICA software (StatSoft, 2004).

Temporal changes in phytoplankton communities in relation to environmental variables were analyzed using multivariate statistical analyses, hierarchical cluster analysis, and non-metric multidimensional scaling (NMDS). Prior to the multivariate statistical analyses, phytoplankton species densities were log transformed to reduce variation. To avoid the problem of $\log (0)$ being undefined, a value of 1 was added to all data points. The data were rescaled in the range of 0 and 1 based on the min-max transformation, giving the same level of importance to all species in the analysis. The analyses were conducted in two steps: cluster analysis for classification and NMDS for ordination of temporal changes in the community.

Cluster analysis was conducted to classify temporal changes in the phytoplankton community in relation to species density at different water depths using Ward's linkage method with Euclidean distance measure. Samples for each water depth were classified into clusters based on the similarities of their community composition. A multiresponse permutation procedure (MRPP; Mielke et al., 1976), which is a nonparametric procedure for testing the hypothesis of no difference between two or more groups of entities, was conducted to evaluate the significance of the clusters. Cluster analysis and MRPP were conducted using PCORD (McCune and Mefford, 1999). Differences in environmental variables among clusters or depths were evaluated using the KW test and Dunn's nonparametric multiple comparison test, using STATISTICA software (StatSoft, 2004).

Indicator species analysis (IndVal; Dufrêne and Legendre, 1997) was used to evaluate indicator species in each cluster defined in the cluster analysis. The indicator value for each species in a group is the product of its relative abundance and its relative frequency $(\times 100)$, and ranges from 0 (no indication) to 100 (perfect indication) (Peterson and Keister, 2003). A perfect indicator of a particular group should be faithful and exclusive to that group, never occurring in another group (McCune and Grace, 2002). Species with an indicator value five times higher than in any other cluster are defined as good indicators (Keister and Peterson, 2003). To determine the significance of species indicator values a Monte Carlo simulation was performed. The analysis was carried out using PCORD (McCune and Mefford, 1999).

NMDS was used to characterize temporal changes in the phytoplankton community at the three depths in the study reservoir. The NMDS technique appears to be superior to other ordination techniques when applied to ecological data (Kenkel and Orloci, 1986; Bettinetti et al., 2000). NMDS was performed using PCORD (McCune and Mefford, 1999), based on the Bray-Curtis distance 

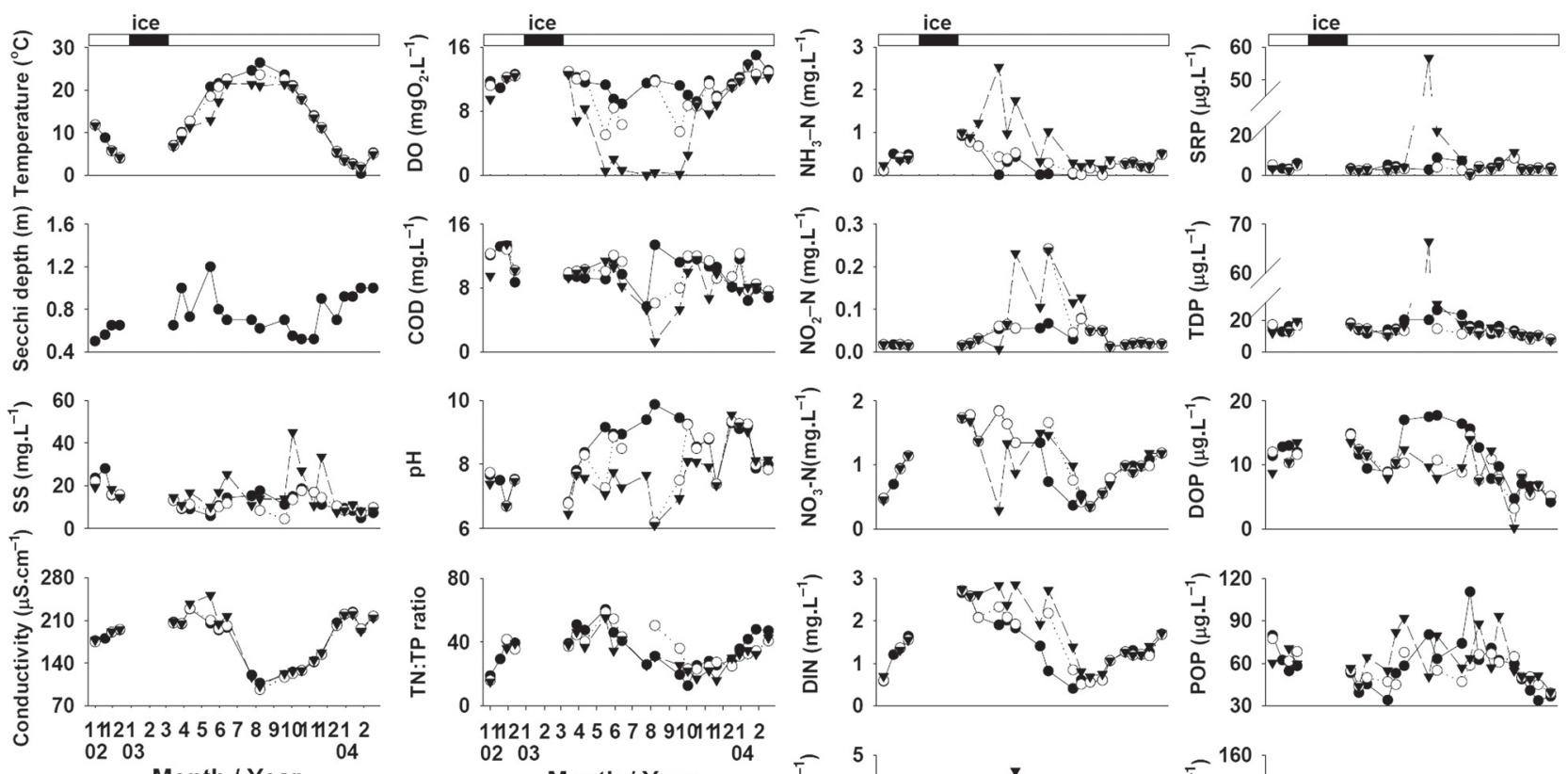

Month / Year
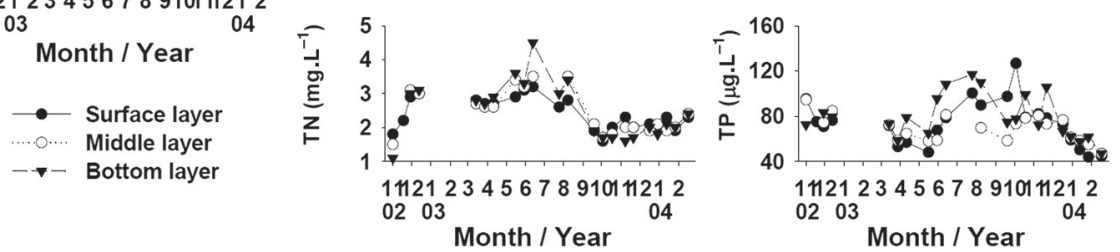

Fig. 2. Temporal variation in environmental variables at three water depths in the Shingu Reservoir from November 2003 to February 2004 (dark bars delineate periods where the reservoir is covered with ice). SS: suspended solids, TN: total nitrogen, DIN: dissolved inorganic nitrogen (the sum of $\mathrm{NH}_{3} \mathrm{~N}, \mathrm{NO}_{2} \mathrm{~N}$, and $\mathrm{NO}_{3} \mathrm{~N}$ ), SRP: soluble reactive phosphorus, TDP: total dissolved phosphorus, DOP: dissolved organic phosphorus, POP: particulate organic phosphorus, TP: total phosphorus.

measure and 100 runs with a maximum of 400 iterations per run. A Monte Carlo test with 99 randomizations was used to determine the probability that the observed stress value of the final solution would occur by chance alone (Laughlin and Abella, 2007). To assist interpretation of the changes in community profiles, Pearson correlation coefficients between dimension scores, and the environmental variables were calculated and plotted using PCORD (McCune and Mefford, 1999).

\section{Results}

\section{Changes in environmental variables}

Most environmental variables showed clear seasonal dynamics at each of the three different depths (Fig. 2). Concentrations of both inorganic and total $\mathrm{N}$ were highest in spring and early summer, lowest in autumn, and increased during winter. The concentrations of all forms of $\mathrm{P}$ were high in summer and autumn, and low in winter and spring. Significant oxygen depletion and a decrease in $\mathrm{pH}$ were observed in the bottom layer in summer, and coincided with high concentrations of $\mathrm{NH}_{3} \mathrm{~N}$ (mean $\pm \mathrm{SD}$; surface: $0.15 \pm 0.28 \mathrm{mg} . \mathrm{L}^{-1}$; middle: $0.39 \pm 0.34 \mathrm{mg} . \mathrm{L}^{-1}$; bottom: $1.03 \pm 0.28 \mathrm{mg} . \mathrm{L}^{-1}$ ) and $\mathrm{NO}_{2} \mathrm{~N}$ (mean $\pm \mathrm{SD}$; surface: $0.06 \pm 0.03 \mathrm{mg} . \mathrm{L}^{-1}$; middle:
$0.15 \pm 0.05 \mathrm{mg} . \mathrm{L}^{-1}$; bottom: $\left.0.19 \pm 0.04 \mathrm{mg} . \mathrm{L}^{-1}\right)$, although they were not significantly different (KW test, $P=0.186$ and 0.149 , respectively) due to their variability. The $\mathrm{NO}_{3} \mathrm{~N}$ was greater in the middle layer (mean $\pm \mathrm{SD}$; surface: $1.14 \pm 0.19 \mathrm{mg} . \mathrm{L}^{-1}$; middle: $1.50 \pm 0.23 \mathrm{mg} . \mathrm{L}^{-1}$; bottom: $\left.1.27 \pm 0.19 \mathrm{mg} . \mathrm{L}^{-1}\right)$ (KW test, $P=0.566) . \mathrm{NH}_{3} \mathrm{~N}(\mathrm{r}=-0.47, P<0.05)$, DIN (r $=-0.45, P<0.05)$ and TN $(\mathrm{r}=-0.35, P<0.05)$ were negatively correlated with $\mathrm{pH}$, whereas $\mathrm{DO}(\mathrm{r}=0.27$, $P<0.05$ ) was positively correlated with $\mathrm{pH}$. DO was most strongly correlated with temperature $(\mathrm{r}=-0.59$, $P<0.05$ ), followed by $\mathrm{NO}_{2} \mathrm{~N}, \mathrm{TP}, \mathrm{NH}_{3} \mathrm{~N}$, TDP, SRP, $\mathrm{TN}$, POP, conductivity, $\mathrm{pH}$ and $\mathrm{SS}(\mathrm{r}$ values $=-0.58$, $-0.42,-0.41,-0.40,-0.39,-0.31,-0.30,0.29,0.27$ and -0.27 , respectively; $P<0.05)$. $\mathrm{NH}_{3} \mathrm{~N}$ showed a significant correlation with DIN $(\mathrm{r}=0.79, P<0.001)$ and TN $(\mathrm{r}=0.61, P<0.001)$. Temperature $(\mathrm{r}=0.63$, $P<0.001)$ and DO $(\mathrm{r}=-0.58, P<0.01)$ were highly correlated with $\mathrm{NO}_{2} \mathrm{~N}$, but DIN ( $\left.\mathrm{r}=0.21, P>0.05\right)$ was not significantly correlated with temperature. TDP and SRP values were more than three times higher in the bottom layer in summer compared to other periods. Electric conductivity was negatively correlated with temperature ( $\mathrm{r}=-0.64, P<0.001)$, with the highest values $\left(251.4 \mu \mathrm{S} . \mathrm{cm}^{-1}\right)$ occurring in the bottom layer in May, and the lowest value $\left(96.0 \mu \mathrm{S} . \mathrm{cm}^{-1}\right)$ occurring in the middle layer in August. TP showed a significant 
a)

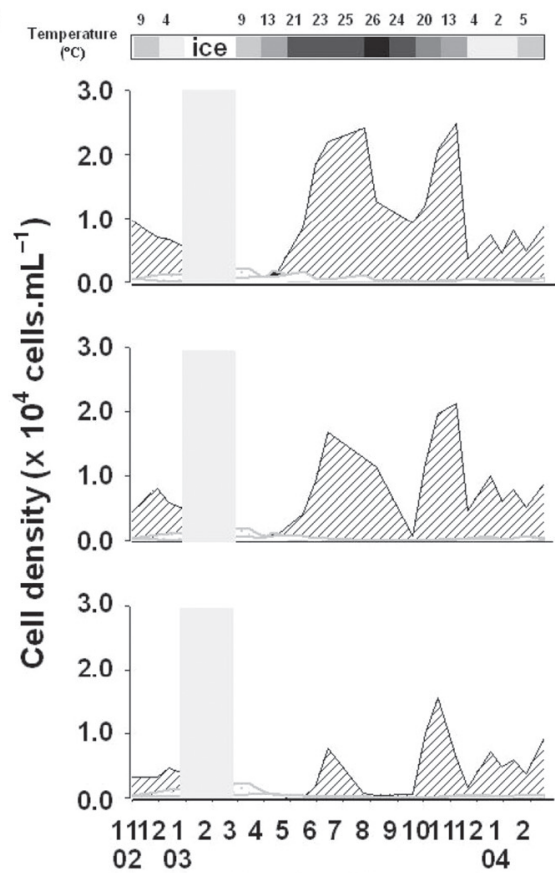

Month / Year b)

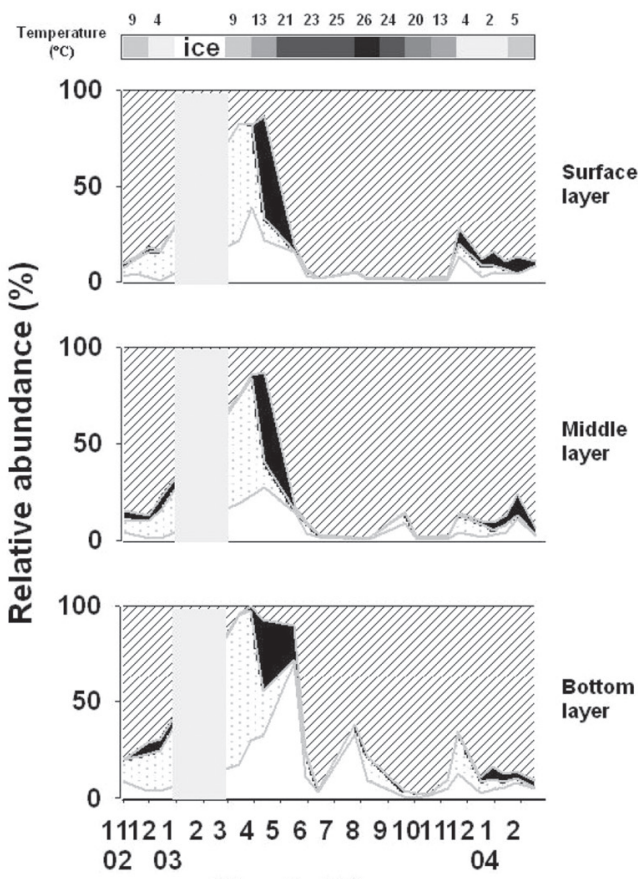

Month / Year

Chlorophyceae एय] Cyanophyceae

Bacillariophyceae

Cryptophyceae and Dinophyceae

Fig. 3. Temporal changes in the phytoplankton community for cell density (a) and relative abundance (b) in the Shingu Reservoir from November 2002 to February 2004 (no data are available for January and February in 2003 because of ice cover).

correlation with POP $(\mathrm{r}=0.90, P<0.001)$ and the TN:TP ratio $(\mathrm{r}=-0.62, P<0.01)$, and $\mathrm{TN}$ showed a significant correlation with DIN $(\mathrm{r}=0.77, P<0.001)$ and the TN:TP ratio $(\mathrm{r}=0.70, P<0.001)$. SD was highest in May $(1.2 \mathrm{~m})$ and showed a negative correlation with SS, which peaked during October and November $(\mathrm{r}=-0.81$, $P<0.001)$. POP showed a significant correlation with SS $(\mathrm{r}=0.62, P<0.01)$.

\section{Changes in phytoplankton community composition}

A total of 66 phytoplankton species were recorded from the three different depths from November 2002 to February 2004; 52 in the surface layer, 50 in the middle layer, and 56 in the bottom layer. Over the whole water column the Chlorophyceae dominated total species richness (36 species), followed by Cyanophyceae (15 species), Bacillariophyceae (12 species), Cryptophyceae (2 species), and Dinophyceae (1 species). However, Cyanophyceae dominated the cell abundance at all depths during the study period, with peak abundance occurring in summer and autumn (Fig. 3a). Other taxonomic groups dominated only during spring, when Cyanophyceae did not occur. Bacillariophyceae dominated only in March and April, and Cryptophyceae dominated only in April and May (Fig. 3b); both showed similar patterns at all three different depths. Chlorophyceae displayed a slightly different pattern, being dominant only in the bottom layer in June. The peak time of Chlorophyceae abundance changed as a function of depth, occurring in the surface layer in March, in the middle layer in April, and in the bottom layer in May. Overall phytoplankton abundance was highest in the surface layer (Dunn's test, $P<0.05$ ) and lowest in the bottom layer (Dunn's test, $P<0.05$ ), and showed a gradient of abundance as a function of depth (Fig. 3b). Bacillariophyceae and Chlorophyceae increased in relative abundance in August and November, especially in the bottom layer.

The abundance of each taxonomic group was a reflection of their dominant species. For example, the abundance of Cyanophyceae was dominated by Microcystis spp. including Microcystis aeruginosa, Bacillariophyceae was dominated by Aulacoseira varians, Cryptophyceae was dominated by Rhodomonas sp., and Chlorophyceae was dominated by Dictyosphaerium pulchellum (Fig. 4). However, slightly different patterns occurred at different depths, particularly in the bottom layer. For the cyanophytes, Oscillatoria sp. (May 2003) and Aphanizomenon sp. (June 2003) dominated before a $M$. aeruginosa bloom occurred in summer; the chlorophyte Monoraphidium contortum was dominant in March, and the bacillariophyte A. ambigua was dominant in November 2003.

Species richness was higher in the surface layer (mean 16.8) than in the bottom layer (mean 14.0) (KW test, $P=0.003$ ), and the Shannon diversity index was higher in the bottom layer (mean 1.4) than in the surface layer (mean 1.2), although the difference was not statistically significant (KW test, $P=0.231$ ) (Fig. 5). However, the Shannon diversity index in the surface layer was 


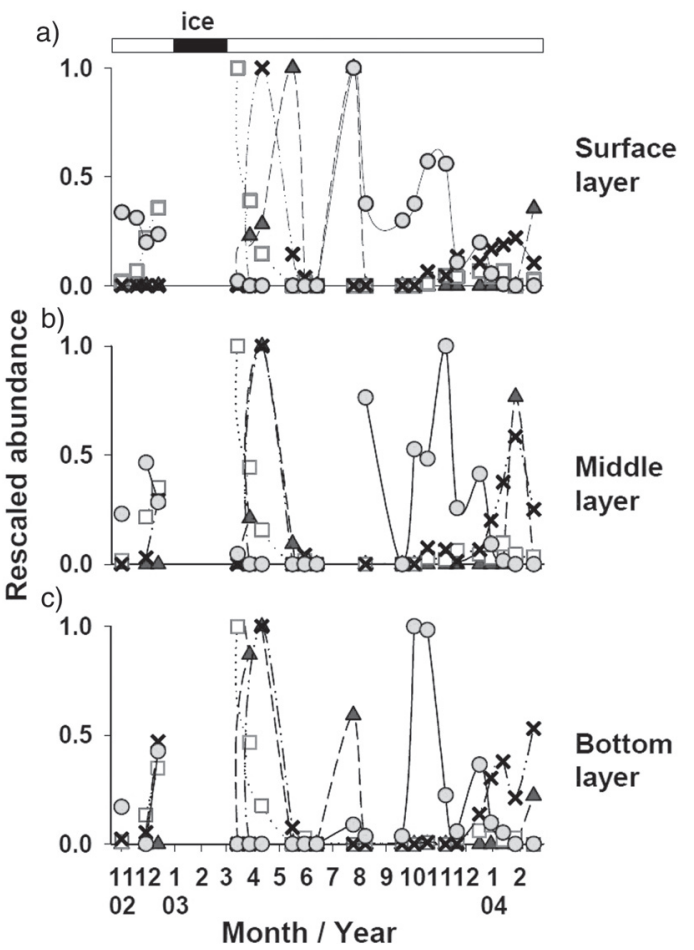

$--\triangle-\sim \quad$ Dictyosphaerium pulchellum - $-\cdot \mathbf{x} \cdot-\cdot \quad$ Rhodomonas sp. Aulacoseira varians

Fig. 4. Changes in the dominant species at three different depths (a: surface, b: middle, c: bottom). Abundance was rescaled between 0 and 1 with min-max transformation.

significantly lower in summer (mean 0.60) than in other seasons (spring: 1.52, autumn: 1.21, winter: 1.22) (Dunn's test, $P<0.05)$, indicating a predominance of cyanophytes during summer.

\section{Community analyses}

\section{Surface layer}

The phytoplankton community in the surface layer was classified into four clusters (I-IV) based on their similarities (Fig. 6a), and displayed clear seasonality. The MRPP showed significant differences among clusters (A $=0.137, P<0.001)$. Samples in November 2002 were classified into cluster III, samples in spring 2003 were in cluster I, samples from June to October 2003 were in cluster II, and samples in winter (from 2003 to 2004) were in cluster IV. Sample names in Figure 6 were identified according to the sampling year (the first two numbers, e.g. 03 for 2003), the sampling month (the next three characters, e.g. AUG for August), and the order of sampling time in the corresponding month at two week intervals (the last number). Some environmental variables including temperature and TP showed significant differences among clusters (KW test, $P<0.05$ ) (Table 1 ), but others including SD, DO, COD, $\mathrm{NH}_{3} \mathrm{~N}, \mathrm{TN}$, and SRP did not. Temperature was significantly higher in cluster II than in other clusters, TP was significantly higher in cluster II than in clusters I and IV, TDP differed significantly between clusters I and III, and the TN:TP ratio differed significantly between clusters I and II (Dunn's test, $P<0.05$ ).

A two-dimensional ordination of NMDS explained $69 \%$ of the variance $(0.34$ and 0.35 of the determination coefficients, $\mathrm{r}^{2}$, for axes 1 and 2 , respectively) in the phytoplankton distance matrix of the surface layer (Fig. 6b). The axes explained significantly more variance than would be expected by chance, based on Monte Carlo permutation tests $(P=0.01)$. Overall, the ordination showed clear seasonal changes in the phytoplankton community. Samples in spring were on the right part of the ordination, samples in summer were on the upper left part, samples in autumn were on the left part, and samples in winter were on the lower part. The arrows in the NMDS ordination show temporal changes in the community from November 2002 to February 2004. Each sample was characterized on the basis of the clusters defined by the cluster analysis (Fig. 6a).

Using the NMDS analysis, species could be ordinated on the biplot based on their contribution to the community ordination (Fig. 6c), reflecting their occurrence at different times. The results were consistent with the IndVal analysis conducted to evaluate indicative species for each cluster; all species presented in the plot had an indicator value $>25 \%$ (Dufrêne and Legendre, 1997). Cluster I was represented with three indicator species including Selenastrum minutum and Aphanocapsa sp., cluster II with two species (Crucigenia rectangularis and Staurastrum astroideum), cluster III with seven species including Ankistrodesmus bibraianus and Nitzschia palea, and cluster IV was with three species including Chlamydomonas sp. (Monte Carlo test, $P<0.05$ ) (Fig. 6c). Good indicators were defined as having an indicator value at least five times higher than in any other cluster (shown in bold).

The effects of environmental variables were characterized by calculating correlation coefficients between environmental factors and NMDS axis scores. The variables having significant correlation coefficients (Pearson correlation coefficient, $P<0.05$ ) are shown as arrows on the NMDS ordination (Fig. 6c), where the arrow length indicates the magnitude of the correlation value and the arrow direction implies a correlation with each axis. Axis 1 was most highly correlated with conductivity $(\mathrm{r}=0.80$, $P<0.05)$, followed by $\mathrm{NH}_{3} \mathrm{~N}(\mathrm{r}=0.75, P<0.05), \mathrm{NO}_{3} \mathrm{~N}$ $(\mathrm{r}=0.72, P<0.05), \mathrm{TP}(\mathrm{r}=-0.68, P<0.05), \mathrm{TN}(\mathrm{r}=0.48$, $P<0.05)$, and $\mathrm{pH}(\mathrm{r}=-0.46, P<0.05)$. Axis 2 was positively correlated with temperature $(\mathrm{r}=0.70$, $P<0.05)$, SS $(\mathrm{r}=0.56, P<0.05)$, and TN $(\mathrm{r}=0.45$, $P<0.05)$, but negatively correlated with DO $(\mathrm{r}=-0.62$, $P<0.05)$. N and $\mathrm{P}$ showed different relationships with the phytoplankton community. High values of conductivity and N-related variables characterized samples in spring (cluster I), whereas high values of P-related variables characterized samples in summer (cluster II).

\section{Middle layer}

The phytoplankton community in the middle layer was classified into four clusters (1-4), and mostly showed 
a)

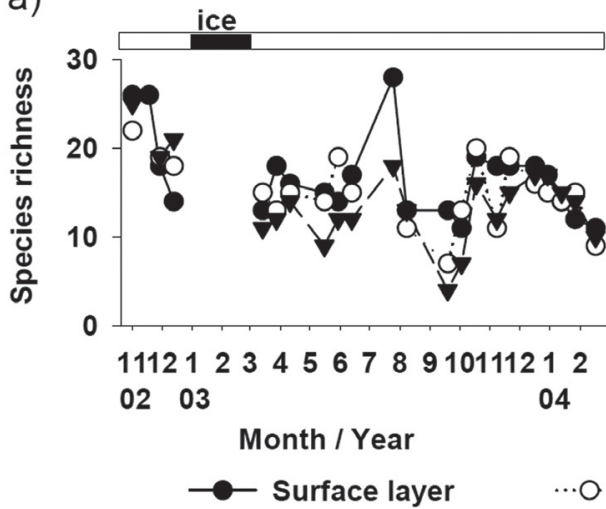

b)

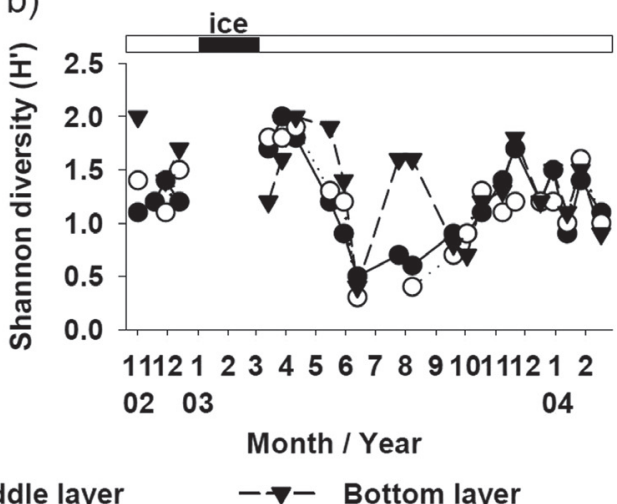

Fig. 5. Changes in species richness (a) and the Shannon diversity index (b) at the three different depths.

a) Euclidean distance

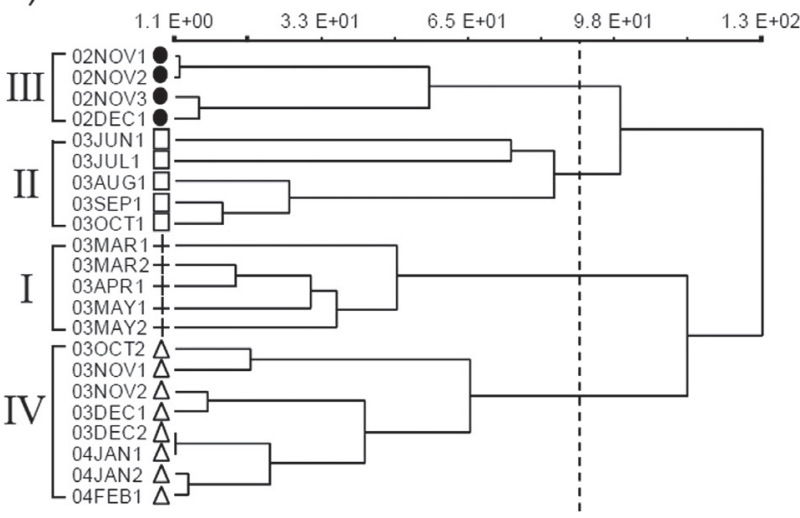

b)

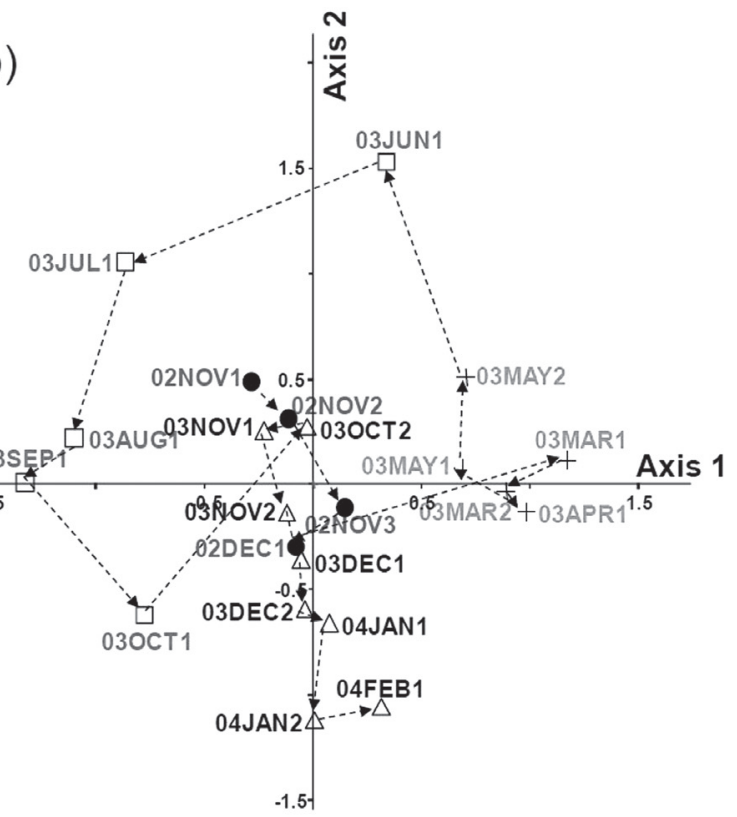

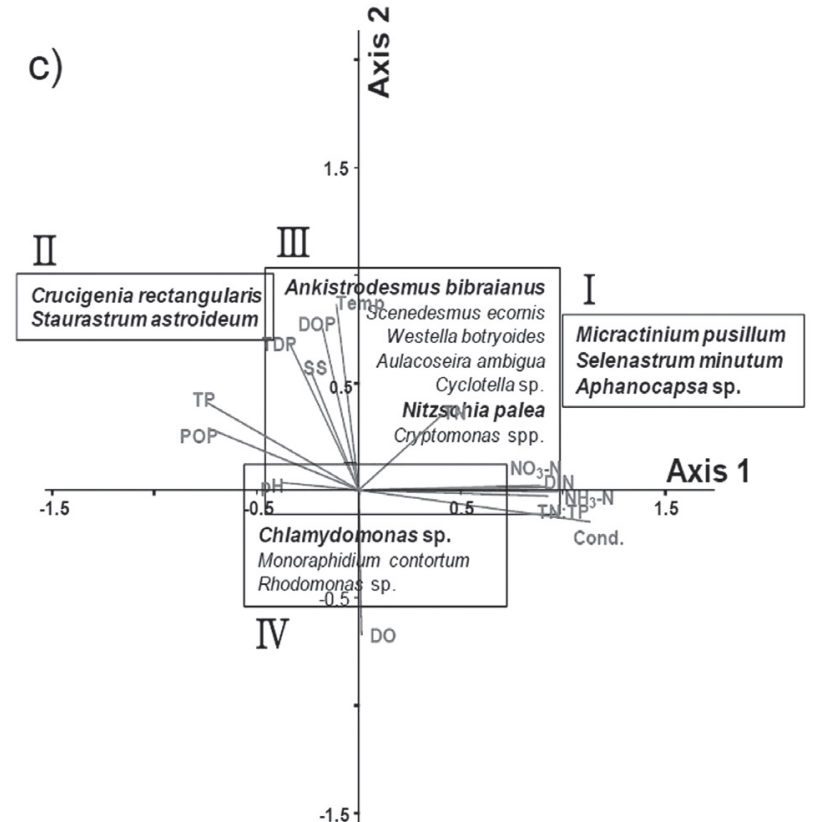

Fig. 6. a) Dendrogram of a hierarchical cluster analysis of the phytoplankton community in the surface layer using the Ward linkage method with Euclidean distance measure. b) NMDS ordination of the phytoplankton community (axis $1: \mathrm{r}^{2}=0.34$, axis $2: \mathrm{r}^{2}=0.35$ ). c) Ordination of species selected using the IndVal analysis with significant environmental variables in the surface layer. Good indicators in each group are bolded, identifying that their indicator values were more than five times higher for that group than for any other groups. 


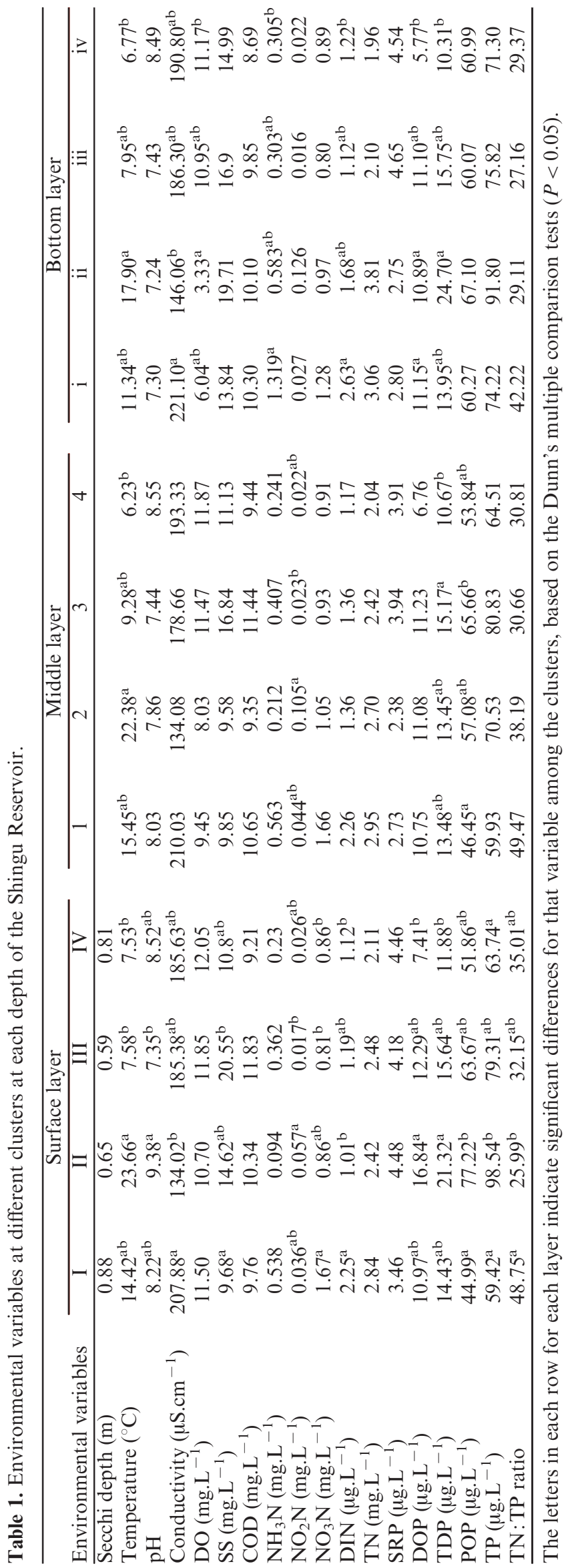

seasonal variation (MRPP, $\mathrm{A}=0.123, P<0.0001$ ) (Fig. 7a). Although the classification was similar to that of the surface layer, the seasonality in the middle layer was weaker than in the surface layer, showing that samples in different seasons were grouped together in different clusters, particularly in cluster 3. Samples in cluster 1 ranged from March to May, and samples in cluster 2 ranged from June to October. Samples in cluster 3 were mixed for November to December 2002, October 2003, and March 2003, and cluster 4 represented samples for autumn and winter (from November 2003 to February, 2004). Environmental variables including temperature, $\mathrm{NO}_{2} \mathrm{~N}$, TDP, and POP showed significant differences among clusters (KW test, $P<0.05$ ) (Table 1$)$. Temperature was significantly different between cluster 2 (highest value) and cluster 4 (lowest value) (Dunn's test, $P<0.05$ ). TDP was highest in cluster 3 and significantly different from cluster 4 (Dunn's test, $P<0.05$ ).

A two-dimensional NMDS ordination explained around $65 \%$ of the variance in phytoplankton community structure in the middle layer (axis $1, \mathrm{r}^{2}=0.27$; axis 2, $\mathrm{r}^{2}=0.48$ ) (Monte Carlo test, $P=0.01$ ) (Fig. 7b). Samples in cluster 3 (Fig. 7a) were more highly scattered than others, and the ordination of samples in time order was slightly mixed compared with that of the surface layer, although they showed seasonality.

Based on the IndVal analysis, cluster 1 was characterized by five indicator species including $D$. pulchellum and Tetrahedron incus, cluster 3 was characterized by seven species including Coelastrum longissima and N. palea, and cluster four was characterized by three species including Chlamydomonas sp. (Monte Carlo test, $P<0.05$ ) (Fig. 7c). However, cluster 2 did not have any indicator species. These characteristics were reflected in the biplot ordination, with the species indicated in bold (D. pulchellum in cluster $1, N$. palea in cluster 3 , and Chlamydomonas sp. in cluster 4) having indicator values for those clusters that were more than 5 times the values in other clusters.

Based on the correlation coefficients between environmental variables and NMDS axis scores, the NMDS axes were significantly correlated with some environment variables, and were visualized on the NMDS ordination map (Fig. 7c) with vector length and direction. Conductivity ( $\mathrm{r}=-0.77, P<0.05), \mathrm{NH}_{3} \mathrm{~N}(\mathrm{r}=-0.56, P<0.05)$, and DIN ( $\mathrm{r}=-0.47, P<0.05)$ were negatively correlated to axis 1 , whereas $\mathrm{NO}_{2} \mathrm{~N}(\mathrm{r}=0.54, P<0.05)$ and temperature (r $=0.45, P<0.05$ ) were positively correlated to axis 1 . Axis 2 was most highly correlated with TDP $(\mathrm{r}=-0.60$, $P<0.05)$, followed by $\mathrm{TP}, \mathrm{NH}_{3} \mathrm{~N}$, and TN ( $\mathrm{r}=-0.49$, $\mathrm{r}=-0.49$ and $\mathrm{r}=-0.46$, respectively, $P<0.05)$.

\section{Bottom layer}

Cluster analysis classified the phytoplankton communities in the bottom layer into four clusters (i-iv) (MRPP, A $=0.109, P<0.0001$ ) (Fig. 8a). The classification showed weak seasonality compared with those of the surface and middle layers. Environmental variables including temperature, conductivity, DO, $\mathrm{NH}_{3} \mathrm{~N}, \mathrm{DIN}$, 

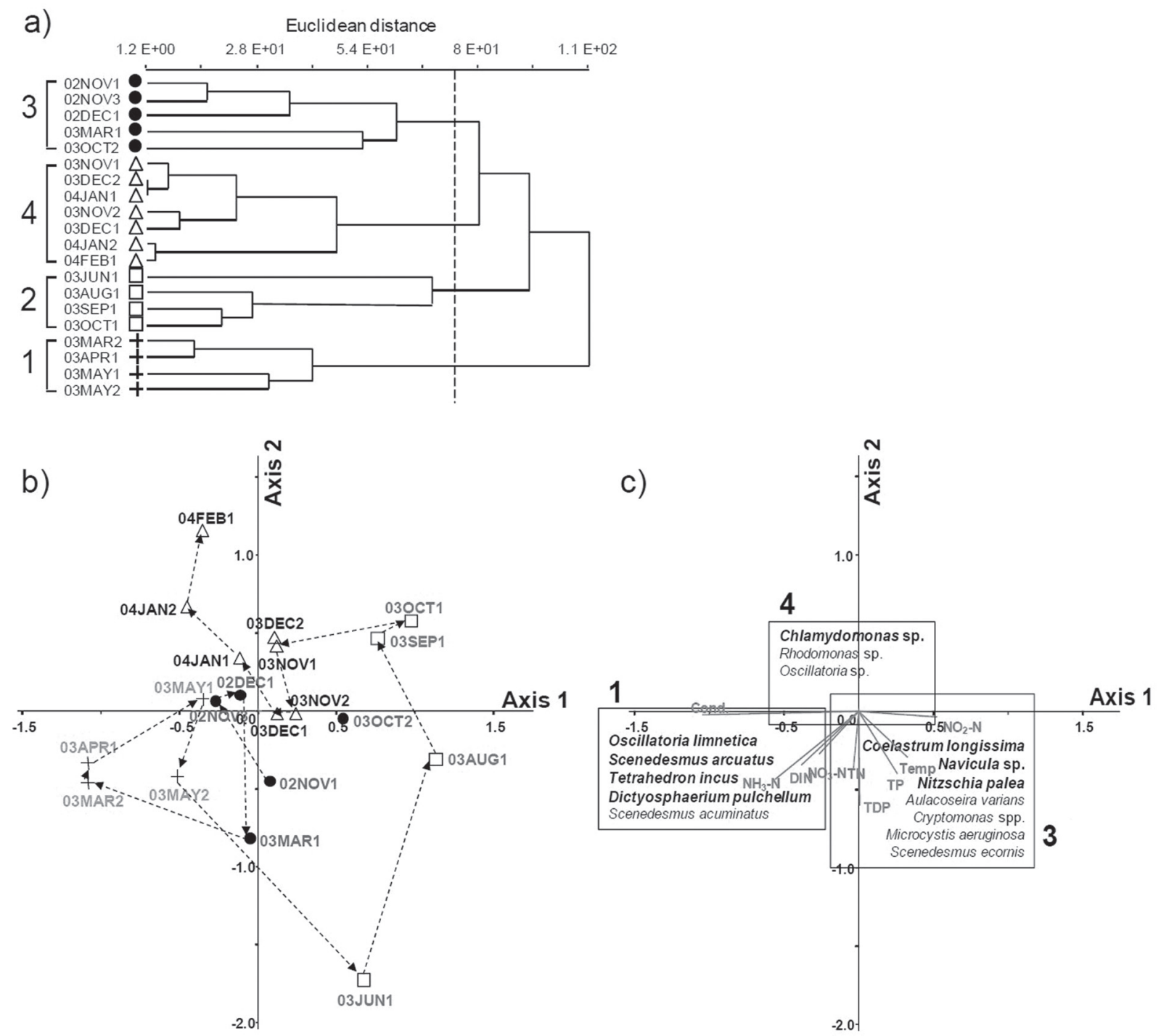

Fig. 7. a) Dendrogram of a hierarchical cluster analysis of the phytoplankton community in the middle layer using the Ward linkage method with Euclidean distance measure. b) NMDS ordination of samples (axis 1: $\mathrm{r}^{2}=0.27$, axis 2: $\mathrm{r}^{2}=0.48$ ). c) Ordination of species selected by the IndVal analysis with significant environmental variables in the middle layer. Good indicators in each group are bolded, identifying that their indicator values were more than five times higher for that group than for any other groups.

DOP, and TDP showed significant differences among clusters (Table $1, \mathrm{KW}$ test, $P<0.05$ ). Temperature was highest in cluster ii and lowest in cluster iv (Dunn's test, $P<0.05$ ), and TDP was significantly different between clusters ii (highest value) and iv (lowest value) (Dunn's test, $P<0.05)$.

The NMDS ordination showed temporal changes in the phytoplankton community, explaining $70 \%$ of the variance (axis $1: r^{2}=0.44$, axis $2: r^{2}=0.26$ ) in the phytoplankton distance matrix (Fig. 8b). As shown in the cluster analysis, the seasonality of the phytoplankton community dynamics in the bottom layer was much weaker than in the surface layer, which showed the strongest seasonality, and the middle layer. In a reflection of the weak seasonality, only two clusters had indicator species based on the IndVal analysis (Monte Carlo test, $P<0.05$ ). Cluster iii was characterized by eight indicator species including
N. palea and Navicula sp., and cluster iv was characterized by two species including Chlamydomonas sp. (Fig. 8c).

The relationship of environmental variables to phytoplankton species composition was examined by correlating variables with NMDS axes scores (Fig. 8c). Axis 1 was highly correlated with TDP and TP $(\mathrm{r}=0.57$ and $\mathrm{r}=48$, respectively; $P<0.05$ ), whereas axis 2 was most highly correlated with conductivity $(\mathrm{r}=0.74, P<0.05)$, followed by $\mathrm{NH}_{3} \mathrm{~N}(\mathrm{r}=0.71, P<0.05)$ and the $\mathrm{TN}$ : TP ratio $(\mathrm{r}=0.63, P<0.05)$. Axis 2 was negatively correlated with TDP $(\mathrm{r}=-0.47, P<0.05)$.

\section{Discussion}

This study has revealed temporal changes of phytoplankton communities in the shallow, hypertrophic 

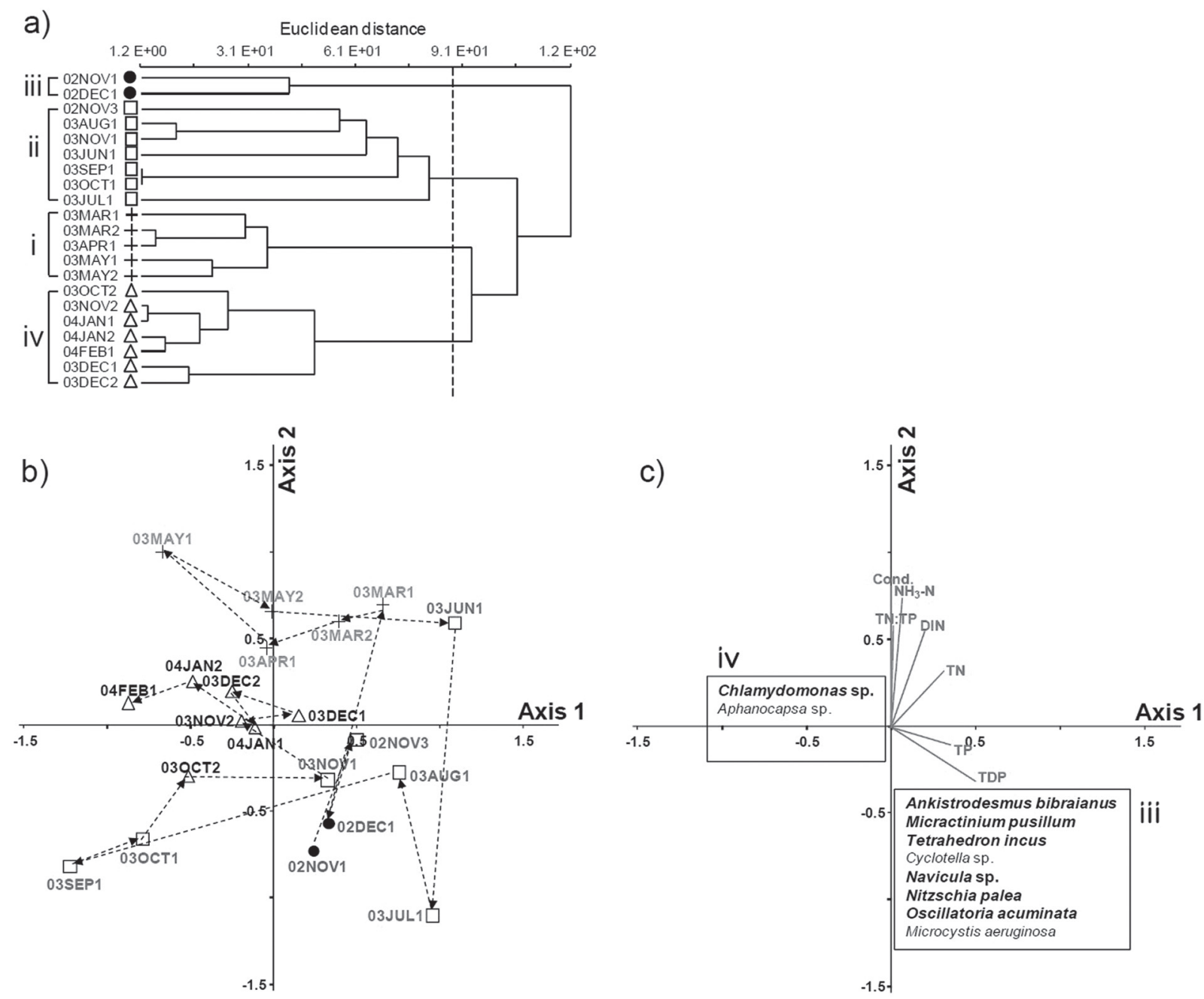

Fig. 8. a) Dendrogram of a hierarchical cluster analysis of the phytoplankton community in the bottom layer using the Ward linkage method with Euclidean distance measure. b) NMDS ordination of samples (axis $1: \mathrm{r}^{2}=0.44$, axis 2: $\mathrm{r}^{2}=0.26$ ). c) Ordination of species selected by the IndVal analysis with significant environmental factors in the bottom layer. Good indicators in each group are bolded, identifying that their indicator values were more than five times higher for that group than for any other groups.

Shingu Reservoir, Korea. With the exception of a short period during spring, Cyanophyceae was the dominant taxonomic group during the study period (Fig. 3). In spring, the dominant group varied among Bacillariophyceae (March and April), Cryptophyceae (April and May), and Chlorophyceae (April and June). Each group was expressed with their dominant species including Oscillatoria spp., Microcystis spp. and Aphanizomenon sp. being the dominant taxa among the Cyanophyceae. These showed a seasonal succession with Oscillatoria spp. dominating in late spring, Aphanizomenon sp. dominating in early summer, and Microsystis spp. dominating in midsummer (Fig. 4). During the study period, Microsystis spp. was the major species causing the algal bloom. The Chlorophyceae were dominated by $D$. pulchellum, the Bacillariophyceae by $A$. varians, and the Cryptophyceae by Rhodomonas sp. Similar results have been reported for the seasonal succession of the phytoplankton community in eutrophic lakes (Reynolds, 1984; Wetzel, 2001). In temperate regions, a bloom of Bacillariophyceae generally occurs in spring, and a bloom of Cyanophyceae occurs from late summer to autumn (Horne and Goldman, 1994). Kim et al. $(2007,2008)$ demonstrated that a supply of the limiting nutrient $(\mathrm{P})$ can compensate for low temperature with respect to the growth of cyanophytes in the Shingu Reservoir.

Both species richness and abundance were greater in the surface layer than in the bottom layer, decreasing as a function of water depth (Figs. 3 and 5). High species richness and abundance in the surface layer, indicating high production, appeared to be related to several environmental factors, particularly temperature and irradiance. Although the temperature was not markedly different between the surface and bottom layers (as the reservoir is shallow), it was significantly related with the ordination axes for the surface and the middle layers, but not the bottom layer (Figs. 6-8). The light intensity differed significantly among the three depths between June 2007 and January 2008 (means of 1046.6, 53.2, and 0.0 Lux in the surface, middle, and bottom layers, respectively) 
(KW test, $P=0.0001$ ). Pinilla (2006) demonstrated that the vertical distribution of phytoplankton exhibits a strong relationship with light intensity, and Oh et al. (2007) showed that daily irradiance is an important limiting factor for primary production in eutrophic conditions. Karacaoglu et al. (2006) revealed that total species richness and abundance are greatly influenced by temperature and irradiance.

Nutrient availability is one of the key factors in the growth of phytoplankton (Huovinen et al., 1999; Wetzel, 2001). However, it is more likely to be important in affecting temporal changes in phytoplankton rather than their vertical distribution. Our results also showed that nutrients ( $\mathrm{N}$ and/or $\mathrm{P}$ ) were significant factors related to the ordination axes at all three different depths, although there were some variations. Turbulence causing vertical mixing may explain the greater similarity of phytoplankton clustering between the surface and middle layers compared to that between the middle and bottom layers (Figs. 6-8). Harris (1986) showed that changes in phytoplankton community structure (diversity, dominance, and biomass) are driven by turbulence and environmental variability.

We also found a strong negative relationship between diversity and biomass production reflected in abundance (Figs. 3 and 5), and similar results were reported by Kokociński and Soininen (2008). Abundance showed two peaks in summer (July and August, 2003) and a peak in autumn (November 2003) at all three water depths (Fig. 3a). The Shannon diversity index for the surface layer was significantly lower in summer, reflecting changes in the community structure in different seasons (Fig. 5b). The low values were due to the Microsystis bloom, while the high values of the diversity index in spring and summer reflected increases in Chlorophyceae, Bacillariophyceae, and Cryptophyceae species.

The evolution of species favors developmental strategies for their growth and survival, and such strategies can be expressed as groups of similar characteristics including morphological, physiological, reproductive, and behavioral factors (Calijuri et al., 2002). These characteristics evolved among species and populations, and allow for better adaptation under varying environmental conditions (Grime, 1979; Calijuri et al., 2002). Several adaptive strategies (CSR strategies) are recognized (Grime, 1977, 1979): C-strategists (competitors), S-strategists (stress tolerant), and R-strategists (disturbance tolerant). Phytoplankton also exhibit adaptive strategies for evolution in different seasons (Reynolds, 1988). In our study, changes of strategies were also revealed in the changes of phytoplankton community structure. In the surface layer, indicator species of cluster III (dominated during autumn) were mostly R-strategists such as $N$. palea and A. ambigua. These species have very low growth thresholds for light and sinking rates, and most are non-motile (Reynolds, 2006). Indicator species in cluster IV (dominated in winter) were C-strategists and included Chlamydomonas sp. and Rhodomonas sp. These species have low growth thresholds for light and generally low sinking rates. M. aeruginosa, which was the dominant species in the study reservoir, is a S-strategist. Such species compete effectively where nutrient resources are depleted by exploiting alternative sources through adaptations such as $\mathrm{N}$ fixation and phosphatase production (Reynolds, 2006).

The multivariate techniques used in this study, including cluster analysis for classification and NMDS for ordination, were useful for characterizing changes in the phytoplankton communities. These techniques should be employed together because they are subject to different sources of distortion (Jiang et al., 2007). The use of ordination techniques has provided insights into the temporal changes in phytoplankton communities (Bettinetti et al., 2000), and NMDS has proved to be a useful tool for this purpose, allowing reliable identification and description of pathways in the chronological succession of phytoplankton (Salmoso, 1996; Bettinetti et al., 2000). Based on the cluster analysis, in the present study, the phytoplankton communities at the three different depths were classified into four clusters that showed strong and significant seasonal differences (Figs. 6a-8a). The seasonality was strongest in the surface layer (Fig. 6a) and weakest in the bottom layer (Fig. 8a). This may reflect differences in the availability and variability of physicochemical factors. These showed greater temporal variation in the surface layer than the bottom layer, and this may have caused phytoplankton changes in the surface layer. For example, the surface layer was characterized in spring (cluster I) by electric conductivity and $\mathrm{N}$, in summer (cluster II) by high values of TP, DOP, and temperature, and in winter (cluster IV) by DO (Fig. 6c). In the middle layer, electric conductivity and DOP were major influencing factors (Fig. 7c), and winter in the bottom layer was characterized by low nitrate (Fig. 8c). Therefore, changes in community structure were influenced by environmental factors including temperature and conductivity, and nutrients including $\mathrm{N}$ and $\mathrm{P}$ at different depths.

Indicator species in each cluster were determined through the IndVal analysis, and these reflected the seasonal succession of phytoplankton. For example, in the surface layer, cluster I (spring) was characterized by Aphanocapsa sp. and S. minutum, cluster II (summer) was characterized by $C$. rectangularis and $S$. astroideum, cluster III (autumn) was characterized by A. bibraianus and $N$. palea, and winter was characterized by Chlamydomonas sp. (Figs. 6c-8c). In the experimental study of the oligotrophic Hyoutaroike pond (Japan), Higashi and Seki (2000) showed that $C$. rectangularis was predominant in summer and C. elongus was predominant in winter. Presently, however, M. aeruginosa was not identified as an indicator species despite being the dominant species causing the summer algal bloom. This was due to the properties of the IndVal analysis. Because indicator values are based on the relative abundance of a species across datasets, species which are highly abundant overall are not necessarily statistically better indicators than species with low abundance (Keister and Peterson, 2003). If a species is present in several different clusters, it is not selected as an indicator species. Microcystis was abundant throughout the year 
and particularly in summer, so was not indicative. In contrast, $S$. minutum was only observed in spring; thus, despite its low abundance, it was selected as a good indicator species for spring in the surface layer. Therefore, although the IndVal analysis is an effective tool for the indicator species, care is needed in the interpretation of the indicator species.

In this study, we investigated phytoplankton succession with related limnological variables at different depths for more than a one year cycle to understand the whole system plankton dynamics in a shallow eutrophic reservoir. Our results demonstrate that although the shallowness (avg. $3.9 \mathrm{~m}$ ) of the system seems to cause more probable turbulence and resuspension of the sediment (Kim, 2004), thereby possibly masking the high nutrient availability especially during the summer when a hypoxic condition is developing at the bottom, the plankton community varied differently along the depth gradient. The significant vertical difference was characterized in particular by a stronger seasonal variation of phytoplankton biomass and composition at the surface layer, depending on seasonally characteristic environmental variables such as temperature, electric conductivity, TP, and TN. The deeper layers also were characterized by different levels of significant seasonality, which was affected by different environmental variables from those of the surface water. These results indicate that depth variation needs to be considered to better understand the whole system phytoplankton dynamics even in the shallow lentic systems.

In a certain period of time, it is probable that there would be a somewhat simple dilution process in the phytoplankton seasonality from the surface to the bottom caused by light attenuation and turbulence ( $c f$. Wetzel, 2001). This could be reflected by quite similar patterns of temporal distribution of phytoplankton cell density and the same patterns of taxonomic succession among three depth layers. However, vertical dynamics of phytoplankton are not simply generalized, because they are the outcome of not only community growth rate but also of the rate phytoplankton are lost from the certain depth of the water column by sedimentation, predation, and other causes of death ( $c f$. Kalff, 2002).

Acknowledgements. This study was supported by the Technology Development Program of the Ministry of Agriculture and Food, Republic of Korea (ARPC grant number: 306009032CG000). YongSu Kwon received a scholarship from the Kyung Hee University for his Master's degree.

\section{References}

Abdul-Hussein M.M. and Mason C.F., 1988. The phytoplankton community of a eutrophic reservoir. Hydrobiologia, 169, 265-277.

APHA, 1995. Standard Methods for the Examination of Water and Wastewater, 19th edition, APHAAWWAWEF, Washington, DC.
Bettinetti R., Morabito G. and Provini A., 2000. Phytoplankton assemblage structure and dynamics as indicator of the recent trophic and biological evolution of the western basin of Lake Como (N. Italy). Hydrobiologia, 435, 177-190.

Brook A.S. and Torke B.G., 1977. Vertical and seasonal chlorophyll a in Lake Michigan. J. Fish. Res. Board Can., 34, 2280-2287.

Calijuri M.C., Dos Santos A.C.A. and Jati S., 2002. Temporal changes in the phytoplankton community structure in a tropical and eutrophic reservoir (Barra Bonita, S.P. Brazil). J. Plankton Res., 24, 617-634.

Chen Y., Qin B., Teubner K. and Dokulil M.T., 2003. Longterm dynamics of phytoplankton assemblages: Microcystisdomination in Lake Taihu, a large shallow lake in China. J. Plankt. Res., 25, 445-453.

Dufrêne M. and Legendre P., 1997. Species assemblages and indicator species: the need for a flexible asymmetrical approach. Ecol. Monogr., 67, 345-366.

Gervais F., Siedel U., Heilmann B., Weithoff G., Heisig-Gunkel G. and Nicklisch A., 2003. Smallscale vertical distribution of phytoplankton, nutrients and sulphide below the oxycline of a mesotrophic lake. J. Plankton Res., 25, 273-278.

Grime J.P., 1977. Evidence for the existence of three primary strategies in plants and its relevance to ecological and evolutionary theory. Am. Nat., 111, 1169-1194.

Grime J.P., 1979. Plant Strategies and Vegetation Processes, John Wiley, New York.

Harris G.P., 1986. Phytoplankton Ecology: Structure, Function and Fluctuation, Chapman and Hall, New York.

Higashi Y. and Seki H., 2000. Ecological adaptation and acclimatization of natural freshwater phytoplankton with a nutrient gradient. Environ. Pollut., 109, 311-320.

Hirose H. and Yamagishi T., 1977. Illustrations of the Japanese Freshwater Algae, Uchidarokakuho, Tokyo, 933 p. (in Japanese).

Horne A.J. and Goldman C.R., 1994. Limnology, McGrow-Hill Inc., New York.

Huisman J., Jonker R.R., Zonneveld C. and Weissing F.J., 1999. Competition for light between phytoplankton species: experimental tests of mechanistic theory. Ecology, 80, 211-222.

Huovinen P.S., Brett M.T. and Goldman C.R., 1999. Temporal and vertical dynamics of phytoplankton net growth in Castle Lake, California. J. Plankton Res., 21, 373-385.

Jiang J.G., Wu S.G. and Shen Y.F., 2007. Effects of seasonal succession and water pollution on the protozoan community structure in an eutrophic lake. Chemosphere, 66, 523-532.

John D.M., Whitton B.A. and Brook A.J., 2003. The Freshwater Algal Flora of the British Isles, An Identification Guide to Freshwater and Terrestrial Algae, Cambridge University Press, New York, USA.

Kalff J., 2002. Limnology: Inland water ecosystems, PrenticeHall, New Jersey.

Karacaoglu D., Dalkiran N. and Dere S., 2006. Factors affecting the phytoplankton diversity and richness in a shallow eutrophic lake in Turkey. J. Freshwat. Ecol., 21, 575-581.

KARICO, 2001. Report of Water Monitoring in Agricultural Reservoirs, S. Korea, Korea Agriculture and Rural Infrastructure Cooperation, Ansan (in Korean).

Keister J.E. and Peterson W.T., 2003. Zonal and seasonal variations in zooplankton community structure off the central Oregon coast, 1998-2000. Prog. Oceanogr., 57, 341-361. 
Kenkel N.C. and Orloci L., 1986. Applying metric and nonmetric multidimensional scaling to ecological studies: some new results. Ecology, 67, 919-928.

Kim H.S., 2004. Study on the growth dynamics and ecotechnological control of algae in reservoirs, Ph.D. Dissertation Thesis, Kunkuk University, Seoul, Korea (in Korean with English abstract).

Kim H.S., Hwang S.J., Shin J.K., An K.G. and Yoon C.G., 2007. Effects of limiting nutrients and $\mathrm{N}: \mathrm{P}$ ratios on the phytoplankton growth in a shallow hypertrophic reservoir. Hydrobiologia, 581, 255-267.

Kim H.S., Hwang S.J. and Konf D.S., 2008. Growth kinetics of phytoplankton in shallow eutrophic reservoir. J. Korean Society on Water Quality, 24, 550-555 (in Korean with English abstract).

Kokociński M. and Soininen J., 2008. Temporal variation in phytoplankton in two lakes with contrasting disturbance regimes. Fund. Appl. Limnol., 171, 39-48.

Laughlin D.C. and Abella S.R., 2007. Abiotic and biotic factors explain independent gradients of plant community composition in ponderosa pine forests. Ecol. Model., 205, 231-240.

McCune B. and Grace J.B., 2002. Analysis of Ecological Communities, MjM Software Design, Gleneden Beach, Oregon, USA.

McCune B. and Mefford M.J., 1999. PCORD. Multivariate Analysis of Ecological Data, Version 4.41, MjM Software, Gleneden Beach, Oregon, USA.

Mielke E.W., Berry K.J. and Johnson E.S., 1976. Multiresponse permutation procedures for a priori classifications. Commun. Stat. Theory Methods, 5, 1409-1424.

Oh H.M., Ahn C.Y., Lee J.W., Chon T.S., Choi K.H. and Park Y.S., 2007. Community patterning and identification of predominant factors in algal bloom in Daechung Reservoir (Korea) using artificial neural networks. Ecol. Model., 203, 109-118.

Padisak J., 1992. Seasonal succession of phytoplankton in a large shallow lake (Balaton, Hungary) a dynamic approach to ecological memory, its possible role and mechanisms. J. Ecol., 80, 217-230.

Peterson W.T. and Keister J.E., 2003. Interannual variability in copepod community composition at a coastal station in the northern California Current: a multivariate approach. Deep Sea Res., 50, 2499-2517.

Pinilla G.A., 2006. Vertical distribution of phytoplankton in a clear water lake of Colombian Amazon (Lake Boa, Middle Caquetá). Hydrobiologia, 568, 79-90.

Prescott G.W., 1962. Algae of the Western Great Lakes Area, Wm. C. Brown Co., Dubuque, Iowa.
Priscu J.C. and Goldman C.R., 1983. Seasonal dynamics of the deep-chlorophyll maximum in Castle lake, California. Can. J. Fish. Aquat. Sci., 40, 208-214.

Ptacnik R., Diehl S. and Berger S., 2003. Performance of sinking and non-sinking phytoplankton taxa in a gradient of mixing depths. Limnol. Oceanogr., 48, 1903-1912.

Reynolds C.S., 1984. Phytoplankton periodicity: the interactions of form, function and environmental variability. Freshwat. Biol., 14, 111-142.

Reynolds C.S., 1988. Functional morphology and adaptive strategies of freshwater phytoplankton. In: Sandgren C.D. (ed.), Growth and Survival Strategies of Freshwater Phytoplankton, Cambridge University Press, Cambridge, 388-433.

Reynolds C.S., 2006. The Ecology of Phytoplankton, Cambridge University Press, Cambridge.

Romo S. and Miracle R., 1994. Long-term phytoplankton changes in a shallow hypertrophic lake, Albufera of Valencia (Spain). Hydrobiologia, 275/276, 153-164.

Salmaso N., 1996. Seasonal variation in the composition and rate of change of the phytoplankton community in a deep subalpine lake (Lake Garda, Northern Italy). An application of nonmetric multidimensional scaling and cluster analysis. Hydrobiologia, 337, 49-68.

Salmaso N., 2002. Ecological patterns of phytoplankton assemblages in Lake Garda: seasonal, spatial and historical features. J. Limnol., 61, 95-115.

Shannon C.E., 1948. A mathematical theory of communication. The Bell System Technical Journal, 27, 379-423.

StatSoft Inc, 2004. STATISTICA (data analysis software system), Version 7, http://www.statsoft.com.

Tilzer M.M., Paerl H.W. and Goldman C.R., 1977. Sustained viability of aphotic phytoplankton in Lake Taho (California Nevada). Limnol. Oceanogr., 22, 84-91.

Valério E., Faria N., Paulino S. and Pereira P., 2008. Seasonal variation of phytoplankton and cyanobacteria composition and associated microcystins in six Portuguese freshwater reservoirs. Ann. Limnol. - Int. J. Lim., 44, 189-196.

Wang X.L., Lu Y.L., He G.Z., Han J.Y. and Wang T.Y., 2007. Exploration of relationships between phytoplankton biomass and related environmental variables using multivariate statistic analysis in a eutrophic shallow lake: A 5-year study. J. Environ. Sci. (China), 19, 920-927.

Wetzel R.G., 2001. Limnology, Lake and River Ecosystems, Academic Press, San Diego, USA.

Winder M. and Hunter D.A., 2008. Temporal organizing of phytoplankton communities linked to physical forcing. Oecologia, 156, 179-192. 